\begin{tabular}{c} 
International Journal of Engineering \& Technology, 7 (3) (2018) $1762-1767$ \\
International Journal of Engineering \& Technology \\
SPC \\
Website: $\begin{array}{c}\text { ww. sciencepubco.com/index.php/IJET } \\
\text { doi: } 10.14419 / \text { ijet.v7i3.13593 } \\
\text { Research paper }\end{array}$ \\
\hline
\end{tabular}

\title{
Water quality analysis and model simulation for the second largest polluted lake in Egypt
}

\author{
Diaa Seif1 $^{1}$ *, Mahmoud Nasr ${ }^{1}$, Mohamed R. Soliman ${ }^{2}$, Medhat Moustafa ${ }^{1}$, Walid Elbarki ${ }^{1}$ \\ ${ }^{1}$ Sanitary Engineering Department, Faculty of Engineering, Alexandria University, Egypt. \\ ${ }^{2}$ Irrigation and Hydraulics Engineering Department Faculty of Engineering, Alexandria University, Egypt \\ *Corresponding author E-mail: eng-diaa.hamdy@alexu.edu.eg
}

\begin{abstract}
This study investigated the spatial variation in the water quality parameters of Burullus Lake using multivariate analysis and MIKE21 model. The lake was classified into zone-1 at north-east (Z1), zone-2 at south-east (Z2), zone-3 at north-middle (Z3), zone-4 at southmiddle (Z4), zone-5 at north-west (Z5), zone-6 at south-west (Z6), and zone-7 at west (Z7). The obtained parameters were temperature $21.5 \pm 5.0^{\circ} \mathrm{C}, \mathrm{pH} 8.2 \pm 0.6$, dissolved oxygen (DO) $5.9 \pm 1.0 \mathrm{mg} / \mathrm{L}$, biological oxygen demand (BOD) $23.9 \pm 5.7 \mathrm{mg} / \mathrm{L}, \mathrm{NH} 3-\mathrm{N} 2.5 \pm 0.3 \mathrm{mg} / \mathrm{L}$, $\mathrm{NO}_{2}-\mathrm{N} 1.9 \pm 0.3 \mathrm{mg} / \mathrm{L}, \mathrm{NO}_{3}-\mathrm{N} 1.2 \pm 0.3 \mathrm{mg} / \mathrm{L}, \mathrm{PO}_{4}-\mathrm{P} 1.9 \pm 0.3 \mathrm{mg} / \mathrm{L}, \mathrm{SiO}_{4} 3.2 \pm 0.1 \mathrm{mg} / \mathrm{L}$, Chlorophyll- $a$ (Chl- $\left.a\right) 88.2 \pm 10.8 \mu \mathrm{g} / \mathrm{L}$, and salinity $3.2 \pm 1.0 \mathrm{~g} / \mathrm{L}$. Principal component analysis showed that agricultural drainage water was the key factor influencing the water quality characteristics of Burullus Lake. Water quality index (WQI) varied between "Bad" to "Medium", suggesting that the lake wasn't suitable for irrigation and fish growth; however, it was appropriate for some aquatic life. A MIKE21 model was developed to provide a recommendation scenario that could be used to enhance the water quality of Burullus Lake. By improving the water quality of precise drains (namely drains 7 and 8), the WQI at Z4 and Z6 modified from "Bad" to "Medium". The period required to achieve this self-purification was 5 months.
\end{abstract}

Keywords: MIKE21 Simulator; Multivariate Statistical Analysis; Spatial Variation; Water Quality Index.

\section{Introduction}

Burullus Lake, receiving a total drainage discharge of $3.9 \times 109 \mathrm{~m}^{3} / \mathrm{y}$, is the second largest lake in Egypt. The lake has been recognized as a consistent water body for the fulfillment of domestic, agricultural, and industrial requirements [1]. Unfortunately, Burullus Lake has become a dumping site for huge amounts of agricultural runoff coming from various sectors/lands of the Delta region. Currently, the lake is facing many challenges, such as eutrophication, high load of contamination, reduction of area, and depletion of fish production [2]. Hence, extensive studies should be conducted to determine the water quality of Burullus Lake.

Principal component analysis (PCA), and cluster analysis (CA) have been used to identify water pollution sources and assess water quality condition. PCA provides deep information on the most meaningful parameters by presenting statistical correlations between measurements [3]. PCA of the normalized variables is executed to extract significant principal components (PCs) by reducing the data set with minimal loss of original information. CA is a group of multivariate techniques performed to describe the relationships between data records. In CA, related parameters are grouped into certain distinct classes in which the parameters within a group are similar to each other (achieve homogeneity). A software package, namely MIKE21, has also been used for modelling various aspects of water quality, complex ecosystem behavior, and ecological applications [4]. It is used to simulate several chemical, physical, and biological processes in water bodies. The Mike 21 software can simulate water environments such as estuaries, oceans, lagoons, and coasts.

Hence, this study was conducted to (a) provide an insight into spatial variations of water quality parameters for Burullus Lake during
2000-2015 according to collected and measured data, (b) identify the relations between water quality parameters using multivariate analysis, (c) estimate the water quality index (WQI), and (d) investigate the possibility of improving the water quality using MIKE21 modeling.

\section{Material and methods}

\subsection{Study area}

Burullus Lake is located in the North-western region of the Nile Delta; i.e., longitude $30^{\circ} 33^{\prime}-31^{\circ} 07^{\prime} \mathrm{E}$ and latitude $31^{\circ} 22^{\prime}-31^{\circ} 26^{\prime}$ $\mathrm{N}$ (figure 1). The lake has dimensions of $47 \mathrm{~km}$ in length, 6-14 km in width, and $0.4-2.1 \mathrm{~m}$ in depth, with an approximate surface area of $410 \mathrm{Km}^{2}[5]$.

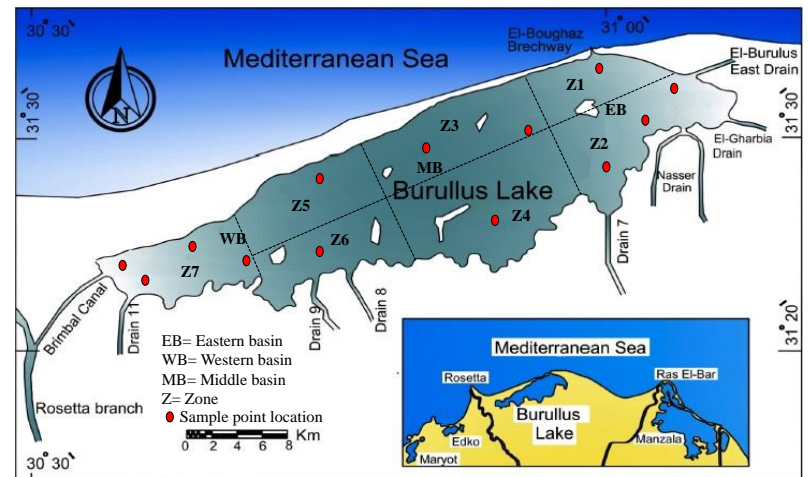

Fig. 1: Study Area of Burullus Lake Showing the Zones and Sampling Point 


\subsection{Water resources}

Burullus Lake water is of brackish nature. A mixture of drain and seawater is the two main sources to the lake. Seepage from the cultivated lands and rainfall in winter are secondary sources [2]. Human activities wastes are discharged to the lake. According to and EEA reports since 2001 to 2015, all drainage system provides the lake with average four hundred million cubic meters annually in creased to be in 2009 about six hundred million cubic meters.

\subsection{Analytical analysis}

In this study, the selected water quality parameters were temperature, $\mathrm{pH}$, dissolved oxygen (DO), salinity, biological oxygen demand (BOD), ammonia-nitrogen $\left(\mathrm{NH}_{3}-\mathrm{N}\right)$, nitrite-nitrogen $\left(\mathrm{NO}_{2}-\right.$ $\mathrm{N})$, nitrate-nitrogen $\left(\mathrm{NO}_{3}-\mathrm{N}\right)$, phosphorus $\left(\mathrm{PO}_{4}-\mathrm{P}\right)$, silicate $\left(\mathrm{SiO}_{4}\right)$ and Chlorophyll- $a$ (Chl- $a$ ) as shown in table 1. The measured parameters were compared with guidelines of the water quality standards of the UNEC and WHO [6-7].

Temperature and $\mathrm{pH}$ were monitored on site with a mercury thermometer and a digital portable $\mathrm{pH}$ meter, respectively. BOD and DO estimated by using Winkler method titration \& membrane electrode method. Water salinity was measured using Bechman salinometer (Model NO. R.S.10). Nutrient salts ( $\mathrm{N}$ and $\mathrm{P}$ species) and Chl- $a$ were measured using a Shimadzu double beam spectrophotometer UV-150-02.

\subsection{Data classification}

The comprehensive database elucidated seven zones in the lake, as follows: zone 1 (Z1), (Z2), (Z3), (Z4), (Z5), (Z6) and (Z7) (Figure. $1)$. This classification was proposed in order to define the best spatial framework for an efficient and reliable water quality assessment of the Lake. Winter data during January - March, spring data taken during April - June, summer data during July - September, while fall data samples from October to December.

The spatial variation of water quality parameters was classified into (Figure 1) zone-1 at north-east (Z1), zone-2 at south-east (Z2), zone-3 at north-middle (Z3), zone-4 at south-middle (Z4), zone-5 at north-west (Z5), zone-6 at south-west (Z6), and zone-7 at west (Z7).

\subsection{Multivariate analysis}

Principal component analysis is designed to rotate the original variables into new and orthogonal variables (axes), called principal components (PCs). This step can be achieved by transforming the original data matrix into a product of two matrices, one of which contains the information about the samples and the other about the variables [3].

The PCs lie along the directions of maximum variance, and thus, provide information on the most meaningful parameters. All calculations were performed using MATLAB R2015a.

\subsection{Water quality index calculation}

Water quality index (WQI) is basically a mathematical tool used to calculate a single output (indicator) from multiple water quality parameters. The calculation of WQI for Burullus Lake was conducted using weighted arithmetic index method. This method classified the water quality according to the degree of purity, using the most commonly measured water quality variables, such as temperature, $\mathrm{pH}$, turbidity, faecal coliform, dissolved oxygen, biochemical oxygen demand, total phosphates, nitrates and total solids $[8,9,10]$.

In this method, each water quality parameter is transferred to a weighting-curve chart in order to obtain a numerical value $(Q i)$. The $(Q i)$ is multiplied by a weighting factor $(W i)$, as described in Eq. 1. Basically, WQI value "water quality status" can be classified as, 0 - 25 "Very bad", 26 - 50 "Bad", 51 - 70 "Medium", 71 - 90 “Good", and 91 - 100 "Excellent”[11].

$W Q I=\sum_{i=1}^{n} Q_{i} W_{i}$

Where:

$(Q i)$ is the sub-index for the water quality parameter; $(W i)$ is weight associated with the water quality parameter; $(n)$ is number of water quality parameters.

Table 1: Average Measurement Parameters of Burullus Lake during Seasons

\begin{tabular}{|c|c|c|c|c|c|c|c|c|c|c|c|}
\hline zone & $\mathrm{Tem}^{\circ} \mathrm{C}$ & $\mathrm{pH}$ & Salinity $\mathbf{g} / \mathbf{L}$ & DO mg/L & $\mathrm{NH}_{3} \mathrm{mg} / \mathrm{L}$ & $\mathrm{NO}_{2} \mathrm{mg} / \mathrm{L}$ & $\mathrm{NO}_{3} \mathrm{mg} / \mathrm{L}$ & $\mathrm{Po}_{0_{4}} \mathrm{mg} / \mathrm{L}$ & Chlorophyll g/L & $\mathrm{Si}_{4} \mathrm{mg} / \mathrm{L}$ & BOD $\mathrm{mg} / \mathrm{L}$ \\
\hline $\mathrm{Z1}$ win & 16.63 & 7.65 & 12.14 & 8.44 & 1.55 & 0.36 & 1.06 & 0.59 & 32.33 & 2.73 & 10.04 \\
\hline \begin{tabular}{|l|} 
Z1 spring \\
\end{tabular} & \begin{tabular}{ll|}
24.87 \\
\end{tabular} & 8.77 & 10.07 & 7.70 & 1.38 & 0.28 & 0.94 & 0.45 & 20.33 & 2.60 & 13.62 \\
\hline \begin{tabular}{|l|} 
Z1 summer \\
\end{tabular} & \begin{tabular}{l|l|}
27.79 \\
\end{tabular} & 8.87 & 8.24 & 7.45 & 1.32 & 0.21 & 0.70 & 0.38 & 28.00 & 2.48 & 13.66 \\
\hline Z1 Fall & 18.55 & 8.15 & 10.63 & 7.94 & 1.46 & 0.36 & 1.03 & 0.56 & 32.55 & 2.60 & 14.14 \\
\hline 2 win & 16.63 & 7.71 & 9.39 & 7.35 & 3.92 & 2.95 & 1.86 & 2.76 & 67.83 & 4.67 & 17.78 \\
\hline \begin{tabular}{|l|} 
Z2 spring \\
\end{tabular} & 24.03 & 8.83 & 5.27 & 5.44 & 3.69 & 2.66 & 1.74 & 2.10 & 88.57 & 4.54 & 26.78 \\
\hline Z2 summer & \begin{tabular}{ll|}
27.79 \\
\end{tabular} & 8.93 & 3.31 & 4.71 & 3.52 & 2.51 & 1.50 & 1.76 & 93.50 & 4.43 & 34.17 \\
\hline Z2 Fall & \begin{tabular}{ll|}
18.29 \\
\end{tabular} & 8.44 & 8.10 & 6.44 & 3.44 & 2.29 & 1.57 & 2.28 & 68.22 & 4.55 & 19.99 \\
\hline $\mathrm{Z}$ win & 15.47 & 7.51 & 3.89 & 7.82 & 1.08 & 0.54 & 0.76 & 0.81 & 54.67 & 3.83 & 16.08 \\
\hline \begin{tabular}{|l|}
$\mathbf{Z} 3$ spring \\
\end{tabular} & 23.84 & 8.63 & 2.08 & 7.28 & 1.02 & 0.42 & 0.64 & 0.69 & 75.40 & 3.72 & 22.60 \\
\hline Z3 summer & 27.19 & 8.73 & 1.04 & 7.02 & 0.97 & 0.36 & 0.45 & 0.52 & 82.80 & 3.63 & 29.81 \\
\hline Z3 Fall & 17.24 & 7.84 & 2.49 & 7.49 & 0.92 & 0.49 & 0.70 & 0.71 & 62.89 & 3.72 & 20.69 \\
\hline$Z 4$ win & 16.40 & 7.16 & 2.26 & 6.05 & 4.00 & 2.26 & 1.87 & 4.28 & 99.00 & 4.82 & 16.78 \\
\hline Z4 spring & 22.02 & 8.28 & 1.14 & 5.04 & 3.80 & 1.56 & 1.75 & 3.43 & 119.73 & 4.69 & 28.65 \\
\hline Z4 summer & 27.87 & 8.38 & 0.68 & 4.43 & 3.69 & 1.41 & 1.51 & 2.43 & 127.13 & 4.57 & 32.76 \\
\hline Z4 Fall & \begin{tabular}{ll|}
18.08 \\
\end{tabular} & 7.99 & 1.83 & 6.25 & 3.66 & 1.77 & 1.17 & 3.25 & 93.59 & 4.67 & 21.99 \\
\hline 25 win & \begin{tabular}{ll|}
14.10 \\
\end{tabular} & 7.34 & 0.88 & 6.77 & 1.60 & 0.68 & 1.28 & 1.59 & 52.33 & 2.05 & 13.58 \\
\hline \begin{tabular}{|l|} 
Z5 spring \\
\end{tabular} & 20.82 & 8.46 & 0.56 & 5.96 & 1.45 & 0.27 & 1.16 & 1.15 & 73.07 & 1.92 & 17.90 \\
\hline $\begin{array}{l}5 \text { summer } \\
\end{array}$ & 26.19 & 8.56 & 0.36 & 5.70 & 1.38 & 0.17 & 0.26 & 0.90 & 80.47 & 1.81 & 25.51 \\
\hline Z5 Fall & \begin{tabular}{ll|}
18.53 \\
\end{tabular} & 7.78 & 0.75 & 6.60 & 1.32 & 0.46 & 0.77 & 1.32 & 63.12 & 1.90 & 18.99 \\
\hline $\mathrm{Z}_{6}$ win & \begin{tabular}{ll|}
17.40 \\
\end{tabular} & 7.26 & 0.79 & 6.84 & 4.90 & 1.18 & 2.32 & 5.10 & 106.00 & 2.94 & 30.17 \\
\hline Z6 spring & \begin{tabular}{ll|}
22.19 \\
\end{tabular} & 8.38 & 0.46 & 3.41 & 4.67 & 0.65 & 2.20 & 4.80 & 124.40 & 2.81 & 50.33 \\
\hline \begin{tabular}{|l|} 
Z6 summer \\
\end{tabular} & 28.25 & 8.48 & 0.29 & 2.94 & 2.21 & 0.50 & 1.35 & 4.54 & 131.80 & 2.70 & 51.50 \\
\hline Z6 Fall & 21.15 & 8.04 & 0.79 & 5.32 & 3.06 & 0.87 & 1.64 & 4.83 & 114.40 & 2.73 & 36.13 \\
\hline$Z 7$ win & \begin{tabular}{ll|}
18.40 \\
\end{tabular} & 7.51 & 0.74 & 6.04 & 2.35 & 0.79 & 1.20 & 0.32 & 140.17 & 2.31 & 19.08 \\
\hline \begin{tabular}{|l|} 
Z7 spring \\
\end{tabular} & 24.02 & 8.63 & 0.42 & 2.96 & 2.34 & 0.59 & 1.08 & 0.20 & 141.73 & 2.18 & 22.80 \\
\hline Z7 summer & 28.33 & 8.73 & 0.24 & 2.09 & 2.15 & 0.44 & 0.41 & 0.17 & 149.13 & 2.06 & 23.51 \\
\hline Z7 Fall & 21.28 & 8.17 & 0.62 & 5.11 & 2.19 & 0.70 & 0.88 & 0.29 & 145.90 & 2.15 & 19.99 \\
\hline
\end{tabular}

\subsection{MIKE21 application}

The numerical model of Mike21 is established according to the solution of the two or three-dimensional incompressible Reynolds averaged Navier-Stokes equations [4]. A finite-element model was used to cover the irregular domain of Burullus Lake with 19509 elements and 9000000 nodes (Figure 2).

Bathymetric charts were presented using an average water depth for a unit area of $150 \mathrm{~m} \times 150 \mathrm{~m}$, and the model domain was discretized into non-overlapping elements/cells.

The Courant number was selected as 0.8 based on the mesh resolution, field velocity, and $100 \mathrm{sec}$ time interval $(2.7 \times 106$ time steps). 
Wind friction was determined from the observation of Egyptian Meteorological Authority according to the wind speed; e.g., wind friction of 0.001255 at $7 \mathrm{~m} / \mathrm{s}$.

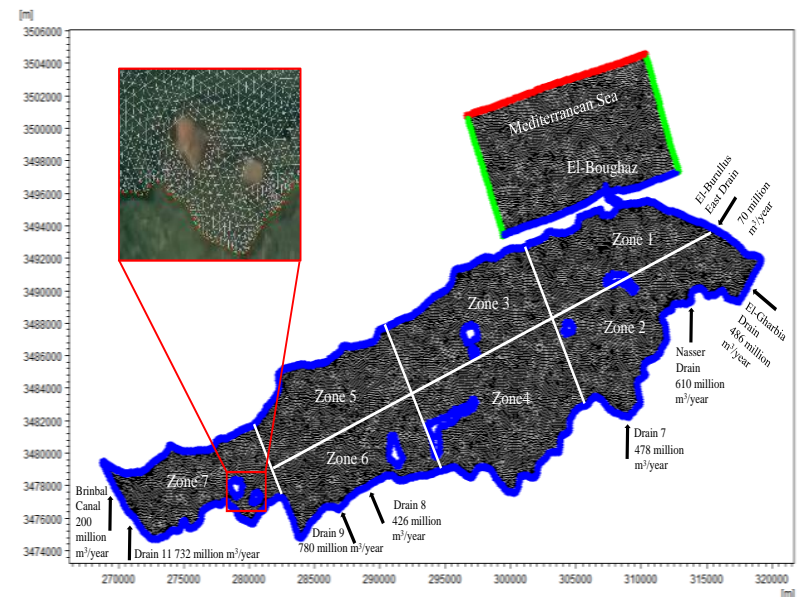

Fig. 2: (2D) Visualization of a Computational Mesh and Drainage Sources of Burullus Lake.

\section{Results and discussion}

\subsection{Water quality variation}

\section{Temperature}

The maximum temperature was found at $\mathrm{Z7}$ reaching $23.0 \pm 4.2^{\circ} \mathrm{C}$, which decreased to $19.9 \pm 5.0^{\circ} \mathrm{C}$ at Z5 (Figure 3a). The non-significant (p: 0.984) variation in temperature could be linked to the small region of latitude (between $31^{\circ} 22^{\prime}$ and $31^{\circ} 26^{\prime} \mathrm{N}$ ).

Hydrogen ion concentration

As shown in Figure 3a, the maximum $\mathrm{pH}$-value was observed at $\mathrm{Z2}$ (8.5 \pm 0.6 ), while the minimum $\mathrm{pH}$ of $7.2-8.4$ was detected at $\mathrm{Z4}$ (p > 0.01 ). Based on WHO [6], Z2 was considered strongly alkaline ( $\mathrm{pH}$ 8.5-9.0), whereas most zones represented a neutral condition $(\mathrm{pH}$ 6.6-7.3). The $\mathrm{pH}$-standards indicated that most data were moderately alkaline in nature, suggesting that the lake was suitable for irrigation, and different kinds of aquatic life [6]. According to UNECE [7], the water quality could be classified as Class I ( $\mathrm{pH}$ 6.5-9.0) for the maintenance of aquatic life. Based on the $\mathrm{pH}$ range of 6.5-8.4, the lake could be used for irrigation purposes [11].

Dissolved oxygen

The horizontal distribution of water quality parameters revealed that DO concentration increased from the western part to the eastern zones (Figure $3 b$ ). Zone-1 showed a significantly ( $<<0.01$ ) high DO level of $7.9 \pm 0.4 \mathrm{mg} / \mathrm{L}$, suggesting a low discharge of irrigation water to the lake. On the contrary, the minimum DO value was observed at Z7 $(4.0 \pm 1.8 \mathrm{mg} / \mathrm{L})$, which could be due to its consumption by microorganisms for the decay of organic pollutants [12]. According to UNECE [8], the DO standard for the maintenance of aquatic life is Class I (DO > 7) at Z1 and Class III (DO $4-6 \mathrm{mg} / \mathrm{L})$ and Class IV (DO 3-4 mg/L) at Z7. Other DO values could be classified as Class II $(6-7 \mathrm{mg} / \mathrm{L})$.

Biological oxygen demand

The highest BOD concentration of $42.0 \pm 10.6 \mathrm{mg} / \mathrm{L}$ was reported at $\mathrm{Z} 6$ (Figure $3 \mathrm{~b}$ ), which could be due to the negative impacts of drains 8 and 9 . These drains carry a high amount of agriculture and municipal drainage water to the lake with a total flow rate of $1.2 \times 109$ $\mathrm{m} 3$ /year (Figure 1). According to UNECE [7], the concentration of total BOD in water bodies for fisheries and aquaculture should not exceed $3 \mathrm{mg} / \mathrm{L}$ at $20^{\circ} \mathrm{C}$. This finding suggested that several zones of Burullus Lake could suffer from high rates of pollution.

\section{Nutrients}

The regional variation of $\mathrm{NH}_{3}-\mathrm{N}$ was fluctuating from $1.0 \pm 0.1$ $\mathrm{mg} / \mathrm{L}$ at $\mathrm{Z} 3$ to $3.8 \pm 0.2 \mathrm{mg} / \mathrm{L}$ at $\mathrm{Z4}$ (Figure $3 \mathrm{c}$ ). The significant ( $\mathrm{p}<$ 0.01 ) spatial variation of $\mathrm{NH}_{3}-\mathrm{N}$ could be due to the discharge of large amounts of drainage water from agricultural sectors through several drains such as Nasser drain and El-Garbiya drain. The decrease in $\mathrm{NH}_{3}-\mathrm{N}$ concentration at $\mathrm{Z} 3$ could be because the zone is not connected to any drain. The drains 7,8 , and 9 carry agriculture contaminants to the lake with a total flowrate of $1.7 \times 109 \mathrm{~m} 3 /$ year; and thus, the $\mathrm{NH}_{3}-\mathrm{N}$ concentrations at zones 4 and 6 increased.

As shown in Figure 3c, a low concentration of $\mathrm{NO}_{2}-\mathrm{N}(0.5 \pm 0.1$ $\mathrm{mg} / \mathrm{L}$ ) was observed at $\mathrm{Z1}$ (a zone not connected to drains). However, the concentration of $\mathrm{NO}_{2}-\mathrm{N}$ increased at $\mathrm{Z} 2(2.2 \pm 0.4 \mathrm{mg} / \mathrm{L})$, $\mathrm{Z} 4(3.3 \pm 0.8 \mathrm{mg} / \mathrm{L})$, and $\mathrm{Z} 6(4.8 \pm 0.2 \mathrm{mg} / \mathrm{L}) . \mathrm{NO}_{2}-\mathrm{N}$ is not a stable nitrogen species and can appear in the water mainly as a result of biochemical oxidation of ammonia (nitrification) or the reduction of nitrate (denitrification) [13].

The spatial variation of $\mathrm{NO}_{3}-\mathrm{N}$ showed the minimum and maximum values of $0.6 \pm 0.1 \mathrm{mg} / \mathrm{L}$ at $\mathrm{Z} 3$ and $1.9 \pm 0.5 \mathrm{mg} / \mathrm{L}$ at $\mathrm{Z6}(\mathrm{p}<0.01)$, respectively (Figure 3d). According to Ayers and Westcot [9], the degree of restriction for $\mathrm{NO}_{3}-\mathrm{N}$ in Burullus Lake on reuse was "None". However, the increase in $\mathrm{NO}_{3}-\mathrm{N}$ concentration over 0.3 $\mathrm{mg} / \mathrm{L}$ suggests the occurrence of eutrophication.

The increased concentration of $\mathrm{PO}_{4}-\mathrm{P}$ at $\mathrm{Z} 2(2.2 \pm 0.4 \mathrm{mg} / \mathrm{L}), \mathrm{Z} 4$ $(3.3 \pm 0.8 \mathrm{mg} / \mathrm{L})$, and Z6 $(4.8 \pm 0.2 \mathrm{mg} / \mathrm{L})$ could result from the discharges of drains [7-9] (Figure 3d). Similarly, El-Zeiny \& ElKafrawy [5] indicated that the increase in the percentage of agricultural and urban lands contributed to an increment of nutrient concentrations in lake ecosystems.

Silicate

The spatial variation of $\mathrm{SiO}_{4}$ indicated the minimum and maximum values of $1.9 \pm 0.1 \mathrm{mg} / \mathrm{L}$ at $\mathrm{Z5}$ and $4.7 \pm 0.1 \mathrm{mg} / \mathrm{L}$ at $\mathrm{Z} 4$, respectively $(\mathrm{p}<0.01)$ (Figure 3e). Zone-5 was not directly connected to drains, and thus observed low $\mathrm{SiO}_{4}$ concentrations (Figure 1). However, the high concentration of $\mathrm{SiO}_{4}$ at $\mathrm{Z} 2$ and $\mathrm{Z} 4$ could be related to the discharge of drainage water coming from several drains such as drain-7, Nasser drain, El-Gharbya drain, and Burullus drain.

Chlorophyll-a

The concentration of Chl- $a$ significantly $(\mathrm{p}<0.01)$ fluctuated from $28.3 \pm 5.7 \mu \mathrm{g} / \mathrm{L}$ at $\mathrm{Z} 1$ (directly connected to the Mediterranean Sea) to $144.2 \pm 4.1 \mu \mathrm{g} / \mathrm{L}$ at $\mathrm{Z7}$ located in the western region (Figure $3 \mathrm{e}$ ). The highest Chl- $a$ concentration was recorded at $\mathrm{Z7}$ because this zone is connected to Rosetta Branch containing several floating and submerged aquatic plants [14]. Moreover, the high concentration of Chl- $a$ at $\mathrm{Z7}$ was possibly associated with the use of phosphorusbased fertilizers within the watersheds of drain-11 and Burullus drain (Figure 1). Chl- $a$ concentration is considered as a good indicator of the phytoplankton biomass, and its increase can reflect a sign of eutrophication. According to UNECE [7], the average Chl$a$ during the year of $88.0 \pm 39.0 \mu \mathrm{g} / \mathrm{L}$ is appropriate for the maintenance of aquatic life, following "Class V".

Salinity

The lowest salinity $(0.5 \pm 0.2 \mathrm{~g} / \mathrm{L})$ was recorded at $\mathrm{Z7}$, whereas $\mathrm{Z1}$ demonstrated the highest salinity of $10.3 \pm 1.6 \mathrm{~g} / \mathrm{L}$, with a p-value < 0.01 (Figure $3 \mathrm{e}$ ). The salinity at $\mathrm{Z7}$ was not affected by the rate of exchange with the sea water because this zone is located far from adjoining open of Mediterranean Sea. Thus, the significant spatial variation in water salinity could be explained by the mixing of Z1 with salty seawater; i.e., Burullus Lake is connected with the Mediterranean Sea through El-Boughaz opening at Z1 (Figure 1). Based on Ayers and Westcot [11], the salinity concentration at Z1 exceeded the severe degree of restriction on reuse $(>2.0 \mathrm{~g} / \mathrm{L})$. According to $\mathrm{FAO} / \mathrm{WHO}$ [15], salinity conditions in $\mathrm{Z7}$ and $\mathrm{Z} 1$ can be classified as "Non-saline" and "Very saline", respectively. However, the average salinity of the lake was medium saline $(2.0-4.0 \mathrm{~g} / \mathrm{L})$ to highly saline $(>4.0 \mathrm{~g} / \mathrm{L})$. 


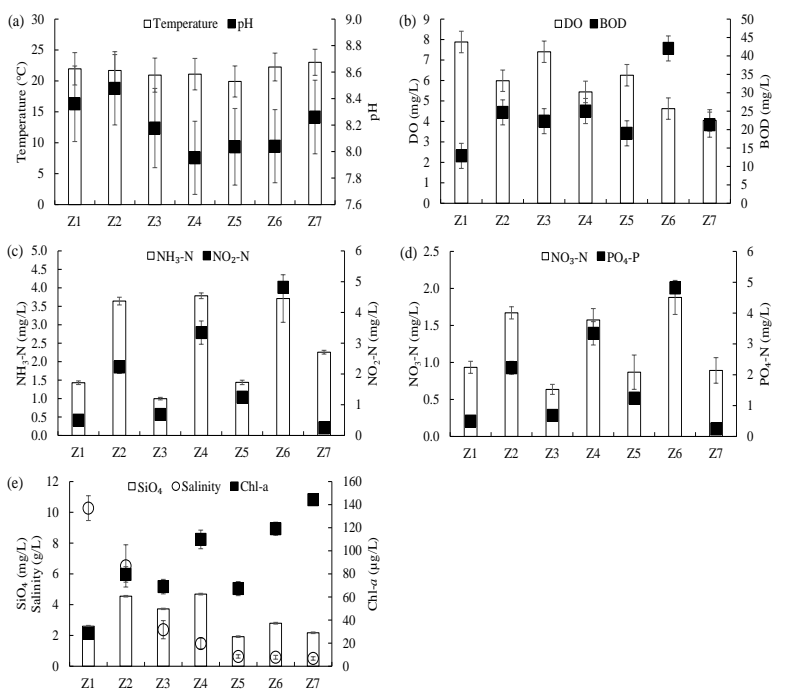

Fig. 3: Spatial Variations of Water Quality Parameters for Burullus Lake: (A) Temperature and $\mathrm{Ph}$, (B) $\mathrm{DO}$ and $\mathrm{BOD}$, (C) $\mathrm{NH}_{3}-\mathrm{N}$ and $\mathrm{NO}_{2}-\mathrm{N}$, (D) $\mathrm{NO}_{3}-\mathrm{N}$ and $\mathrm{PO}_{4}-\mathrm{P}$, and (E) $\mathrm{Sio}_{4}$, Salinity, and Chl- $a$.

\subsection{Principal component analysis}

The first two principal components (i.e., PC1, and PC2) affected the quality of the lake with a total variability of $68 \%$. The first principal component (PC1: $39 \%$ of the variance) represented high loadings on BOD: 0.36, $\mathrm{NH}_{3}-\mathrm{N}: 0.43, \mathrm{NO}_{3}-\mathrm{N}: 0.38, \mathrm{PO}_{4}-\mathrm{P}: 0.40$, and Chl- $a$ : 0.34 (Figure 4a). These positive loadings indicated that PC1 increased with nutrients concentrations coming from agricultural land. In addition, DO was distributed on the negative side of PC1, suggesting that the discharge of drainage water into the lake tended to reduce the oxygen content. This result indicated that agricultural drainage water was the key variable influencing the water quality characteristics of Burullus Lake. The second principal component (PC2: 29\% of the variance) was associated with high positive loadings on temperature: 0.44 and $\mathrm{pH}: 0.36$, and a negative loading on DO: -0.38 (Figure 4a). This finding indicated an opposite correlation between temperature and DO, suggesting that DO concentrations tended to decrease in summer. BREABÂN [16] reported that the peak levels of DO in winter could be because the solubility of oxygen increases as water temperature decreases.

Cluster analysis

According to Figure 4b, the samples were distributed into two groups:

Cluster 1: positioned at the right part of PC1 and contained mainly the zones of Z2, Z4, and Z6. Since organic substances and nitrogen and phosphorus species had strong positive loadings in PC1, these zones were mainly influenced by nutrients concentrations coming from agricultural lands and catchment run-off processes. Zone-2 is located near a large population community, discharging domestic sewage to El-Gharbya drain and Burullus drain. Zone-4 is near drain 7 that carries huge amounts of agricultural drainage water (478×106 m3/year). Zone- 6 receives discharges coming from drain-8 (426×106 m3/year) and drain-9 (780×106 m3/year).

Cluster 2: containing the zones Z1, Z3, and Z5, was approximately distributed on the negative direction of PC1. Zone-1 is located in the Eastern basin, indicating that it was affected by high salinity due to the influence of the exchanges with the Mediterranean Sea (Figure 1). The zones $Z 3$ and $Z 5$ are located far from the drainage water, and thus they were characterized by low nutrient concentrations and an increase in DO levels.

Zone-7 was distributed on the positive direction of PC2, indicating that this zone suffered from increased chlorophyll-a concentrations, and low DO levels. This result might be due to the decrease of flow rate coming from Rosetta Branch, leading to poor water circulation [12]. Moreover, the lack of hydrodynamic water circulation in the lake contributed to the appearance of dead zones, such as zone 7 [17].
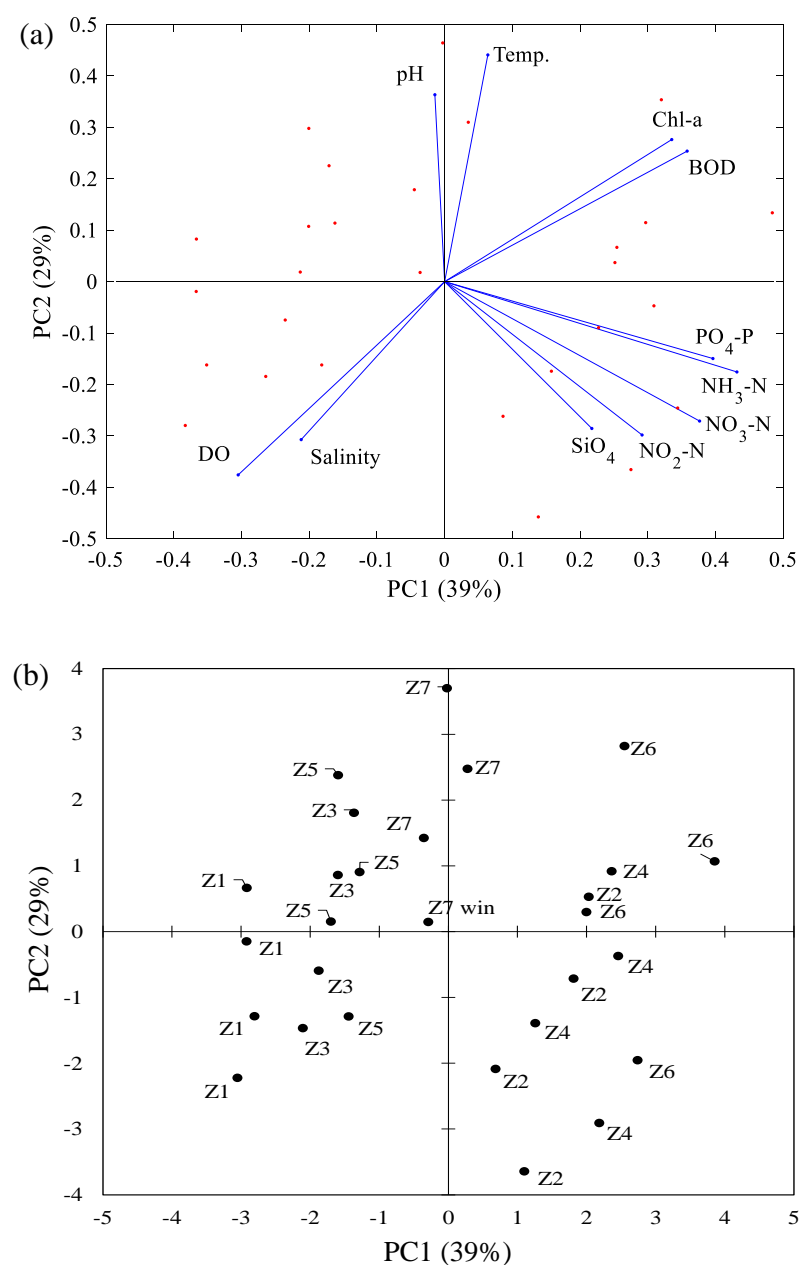

Fig. 4: Multivariate Analysis of Water Quality Parameters for Burullus Lake: (A) Principal Component Analysis, and (B) Cluster Analysis.

\subsection{Water quality index}

The results indicate that is no seasonal difference in WQI values can be obviously witnessed because the lake temperature could be linked to the small region of latitude between $31^{\circ} 22^{\prime}$ and $31^{\circ} 26^{\prime}$ $\mathrm{N}$. As might be expected, the WQI decreased during the summer season (Figure 5a). The WQIs of zones 2, 4, and 6 were found between 30 and 40, referring to "Bad" water quality type (Figure 5b). The low WQI in these zones could potentially increase the risk for health-related problems. Zone-2 suffered from organic and nutrients loads coming from several drains. These drains include (a) ElBurullus drain that carries average waste of $70 \times 106 \mathrm{~m}^{3} /$ year of untreated and industrial wastewater, (b) El-Gharbya drain, Nasser drain, and drain-7 carrying about $1.6 \times 109 \mathrm{~m}^{3} / \mathrm{year}$ of sewage and agricultural drainage water. In addition, $\mathrm{Z} 4$ and $\mathrm{Z} 6$ were affected by the discharge of untreated wastewater coming from many small villages and communities distributed along drain side areas, reaching over $1.0 \times 109 \mathrm{~m}^{3} /$ year.

The zones Z1, Z3, Z5, and Z7 were categorized as "Medium" water quality type. The highest salinity was reported in $Z 1$ due to the mixing of Burullus Lake and Mediterranean Sea [2]. Zone-3 could be affected by the pollution coming from drain-7 $\left(478 \times 106 \mathrm{~m}^{3} /\right.$ year $)$. Additionally, zone- 3 is connected to Khalig canal and Nasser drain. Zones 5 and 7 are located near Brimbal canal and drain-11, discharging approximately $932 \times 106 \mathrm{~m}^{3} /$ year of agricultural discharges [5]. 

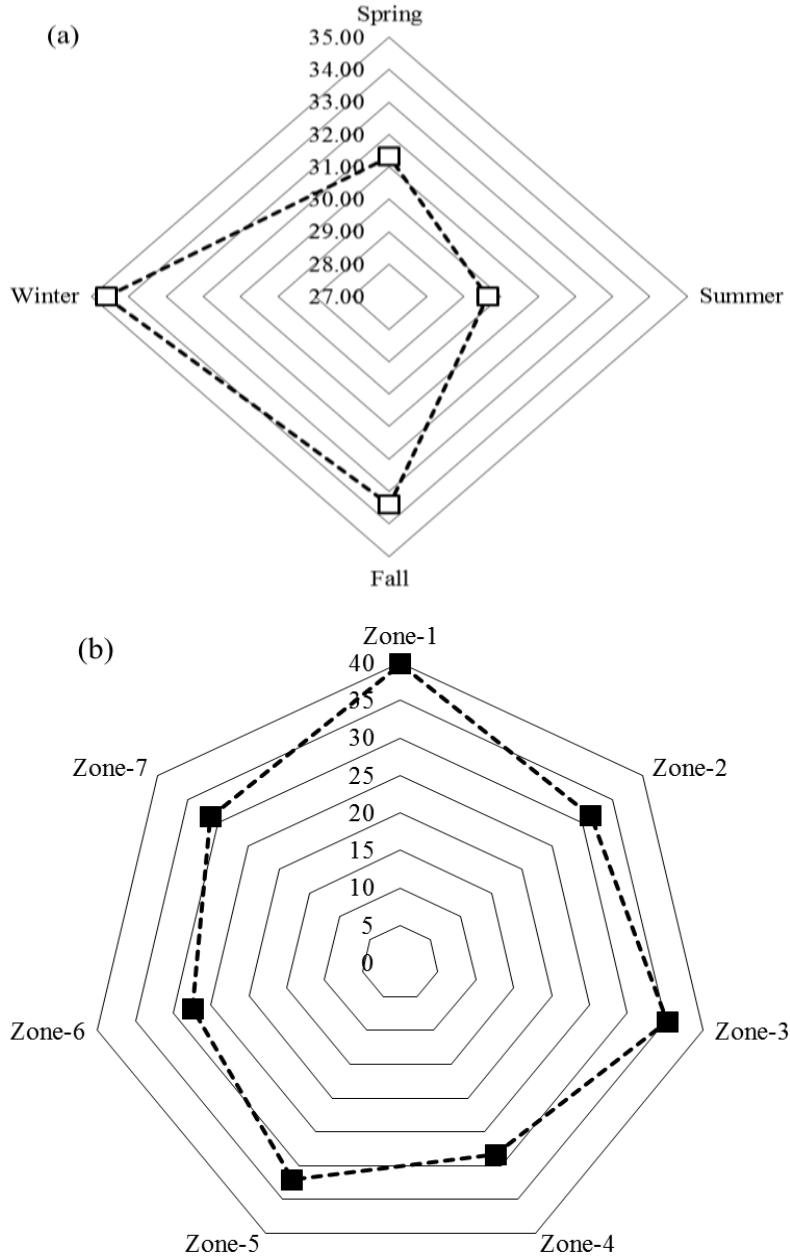

Fig. 5: Water Quality Index for Lake Burullus: (A) At Seasonal, (B) At Spatial.
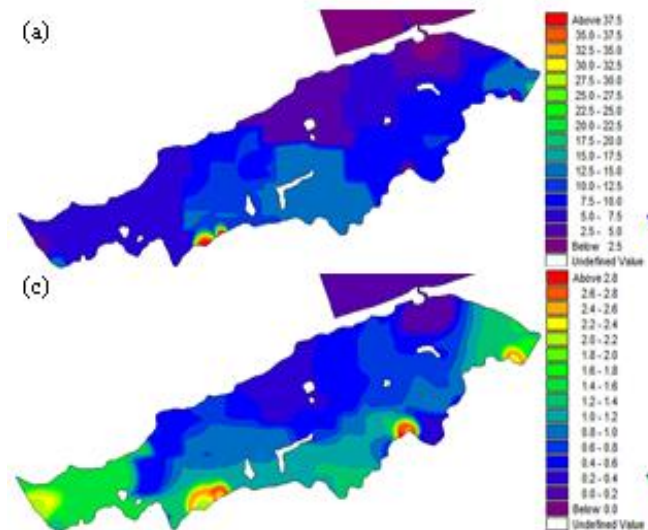

(e)

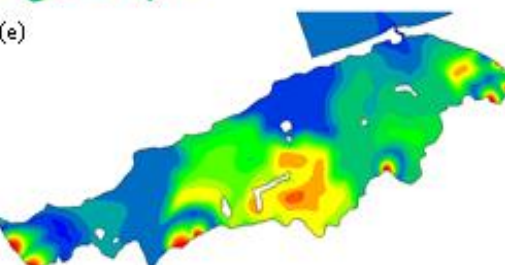

(g)

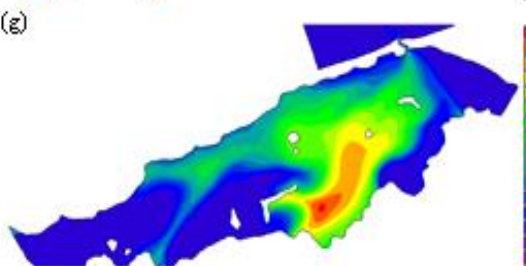

\subsection{Simulation by MIKE21 model}

Model calibration and validation

The model was subjected to a calibration procedure to estimate its applicability for fitting the collected data. The model parameters of both hydrodynamic and ecological models were iteratively adjusted until the model results agreed with the measured data. It was found that the coefficients of determination $\left(\mathrm{R}^{2}\right.$-values) of water quality parameters were 0.95 for BOD (Figure 6a), 0.74 for $\mathrm{NH}_{3}-\mathrm{N}$ (Figure 6b), 0.62 for $\mathrm{NO}_{3}-\mathrm{N}$ (Figure 6c), and 0.93 for $\mathrm{PO}_{4}-\mathrm{P}$ (Figure 6d). The calibrated parameters included nitrification rate: 2.3/day, $\mathrm{NH}_{3-}$ $\mathrm{N}$ yield by plants $0.078 \mathrm{~g}-\mathrm{N} / \mathrm{g}-\mathrm{DO}$, denitrification rate $1.03 /$ day, BOD decay rate: $0.47-2.24 /$ day, and half-saturation oxygen concentration: $2.1 \mathrm{mg} / \mathrm{L}$.

The validation procedure was conducted over a period of one year using new data that were not involved in calibration. The progress of validation was confirmed by the determination of $\mathrm{R}^{2}: 0.92-0.95$, and adj- $\mathrm{R}^{2}: 0.87-0.91$. This result ensured the model reliability and usability.

Water quality improvement

The developed model was used to provide a recommendation scenario that could be used to enhance the water quality of Burullus Lake. The values of physicochemical parameters for drains 7 and 8 were assumed to be allowable according to UNECE [7]. The pollutants in drains can be minimized by (a) reducing the agricultural discharge that contains pesticides and washed and leached fertilizers, (b) using small communities with separate treatment plants that allow for wastewater reuse in irrigation purposes, (c) restricting the over-application of fertilizers by using biological methods to resist the agricultural pests. Under this scenario, the water quality parameters of Burullus Lake improved as follows: BOD from 23.9 to 9.2 $\mathrm{mg} / \mathrm{L}$ (Figure 6e), $\mathrm{NH}_{3}-\mathrm{N}$ from 2.5 to $0.8 \mathrm{mg} / \mathrm{L}$ (Figure $6 \mathrm{f}$ ), $\mathrm{NO}_{3}-\mathrm{N}$ from 1.2 to $0.4 \mathrm{mg} / \mathrm{L}$ (Figure $6 \mathrm{~g}$ ), and $\mathrm{PO}_{4}-\mathrm{P}$ from 1.9 to $0.5 \mathrm{mg} / \mathrm{L}$ (Figure 6h). In addition, the WQI at Z4 and Z6 improved from "Bad" to "Medium". It was found that the period required to achieve this self-purification could be 5 months. 


\section{Conclusion}

This study succeeded to develop a large-scale picture of water quality in Burullus Lake and it can be concluded that:

Seasonally, significant $(\mathrm{p}<0.05)$ variations were observed in temperature and $\mathrm{PH}$, however significant $(\mathrm{p}<0.05)$ spatial differences were determined in salinity, $\mathrm{DO}, \mathrm{NH}_{3}-\mathrm{N}, \mathrm{NO}_{2}-\mathrm{N}, \mathrm{NO}_{3}-\mathrm{N}, \mathrm{PO}_{4}-\mathrm{P}$, Chl-a, and $\mathrm{SiO}_{4}$.

According to PCA results, PC1: $39.01 \%$ represented high loadings on $\mathrm{NH}_{3}-\mathrm{N}$ : 0.43, $\mathrm{NO}_{3}-\mathrm{N}$ : 0.38, BOD: 0.36 and $\mathrm{PO}_{4}-\mathrm{P}: 0.40$, whereas PC2: $29.19 \%$ was associated with high positive loadings on salinity: 0.42 and $\mathrm{pH}: 0.57$, and with a negative loading on Chl- $a$ : -0.22 .

The results from cluster analysis revealed that zones 2,4 and 6 (located in the southern part of the lake) were mainly influenced by nutrients concentrations coming from agricultural drainage water, while zone 7 (located in the western part of the lake) suffered from increased Chl- $a$ concentrations, and lower DO levels.

Zone- 1 was affected by high salinity due to the influence of the exchanges with the Mediterranean Sea, while zones 3 and 5 (situated in the northern part of the lake) were subject to lower pollution. A simulation model using MIKE21 software provided an enhancement scenario to modify the WQI of Z4 and Z6 from "Bad" to "Medium" within 5 months.

In conclusion, the lake water was not adequate for drinking as a surface water sources or irrigation purposes or even as a fish farm. However, it can be suitable for some aquatic habitats and plants.

Thus, it is recommended to:

1) Control the discharge of drainage water and sewage discharged into the lake.

2) Reduce the usage of fertilizers in agricultural sectors.

3) Improve the quality of agricultural drainage water coming to the lake by providing an appropriate treatment method.

Further investigations should be conducted to studying the possibility of dividing the lake into separate parts and providing mechanical aeration system to improve water quality to be suitable as a fish farms.

\section{References}

[1] K. Shaltout, "Reed Products from Lake Burullus, Egypt" The Wetland Book, Netherlands: Springer, 2017. https://doi.org/10.1007/978-94-007-6172-8 211-8.

[2] H. El-Asmar, M. Hereher and S. El Kafrawy, "Surface area change detection of the Burullus Lagoon, North of the Nile Delta, Egypt, using water indices: A remote sensing approach," The Egyptian Journal of Remote Sensing and Space Science, Vol. 16, No. 1, pp. 119 123, 2013. https://doi.org/10.1016/j.ejrs.2013.04.004.

[3] M. Nasr and H. Zahran, "Performance evaluation of agricultural drainage water using modeling and statistical approaches," The Egyptian Journal of Aquatic Research, Vol. 42, No. 2, pp. 141-148, 2016. https://doi.org/10.1016/j.ejar.2016.04.006.

[4] DHI, MIKE 11-A "Microcomputer Based Modelling System for Rivers and Channels," Technical Reference. Version 2008, Denmark: Danish Hydraulic Institute, 2008

[5] A. El-Zeiny and S. El-Kafrawy, "Assessment of water pollution induced by human activities in Burullus Lake using Landsat 8 operational land imager and GIS," The Egyptian Journal of Remote Sensing and Space Science, Volume 20, Pages S49-S56, 2017. https://doi.org/10.1016/j.ejrs.2016.10.002.

[6] WHO, "Guidelines for drinking-water quality," Second ed, Vol. 2 Health criteria and other supporting information, Geneva: World Health Organization (WHO), 1996

[7] UNECE, "Protection and Sustainable Use of Water Resources and Aquatic Ecosystems," New York: United Nations Economic Commission for Europe (UNECE), 1995.

[8] Roșu, C., Piștea, I., Călugăr, M., Martonoș, I., Ozunu, A., "Assessment of ground water quality status by using water quality index (WQI) method in Tureni village," Cluj county, Aerul siapa componente ale mediului, pg 111-118, 2013 Cluj-Napoca, Romania.

[9] Piștea, I., Roșu, C., Martonoș, I., Ozunu, A., "Romanian surface water quality: Tarnava Mare river between Medias and Copsa Mica case study," Environmental Engineering and Management Journal,
Vol.12, No. $\quad 2, \quad 283-289, \quad 2013$. https://doi.org/10.30638/eemj.2013.034.

[10] Iticescu, C., Georgescu, L.P., Topa, C. M. - "Assessing the Danube water quality index in the city of Galati, Romania," Carpathian Journal of Earth and Environmental Sciences, Vol 8, No 4, 2014.

[11] R. Ayers and D. Westcot, "Water quality for agriculture. Rome: FAO Irrigation and Drainage," Paper 29. Revision. 1. pp. 1-130, 1994

[12] H. Hossen and A. Negm, "Change detection in the water bodies of Burullus Lake, Northern Nile Delta, Egypt, using RS/GIS," Procedia Engineering, Vol. 154, pp. 951-958, 2016 https://doi.org/10.1016/j.proeng.2016.07.529.

[13] J. Lai, F. Jiang, K. Ke, M. Xu, F. Lei and B. Chen, "Nutrients distribution and trophic status assessment in the northern Beibu Gulf, China," Chinese Journal of Oceanology and Limnology, Vol. 32, No. 5, pp. 1128-1144, 2014. https://doi.org/10.1007/s00343-014-3199-y.

[14] M. Nassar and S. Gharib, "Spatial and temporal patterns of phytoplankton composition in Burullus Lagoon, Southern Mediterranean Coast, Egypt," The Egyptian Journal of Aquatic Research, Vol. 40, No. 2, pp. 133-142, 2014. https://doi.org/10.1016/j.ejar.2014.06.004

[15] FAO/WHO, "Contaminants," In: Codex Alimentarius, Vol. XVII and Rome: FAO/WHO, Codex Alimentarius Commision, 1984.

[16] I. BREABĂN, D. GHETEU and M. PAIU, "Determination of Water Quality Index of Jijia and Miletin Ponds," Bulletin of the University of Agricultural Sciences \& Veterinary, Vol. 69, No. 2, p. 160, 2012.

[17] M. Okbah and N. Hussein, "Impact of Environmental Conditions on the Phytoplankton Structure in Mediterranean Sea Lagoon, Lake Burullus, Egypt," Water, Air, and Soil Pollution, Vol. 172, No. 1-4, pp. 129-150, 2006. https://doi.org/10.1007/s11270-005-9066-X. 